\title{
The Effect of Educational Intervention on Care Dependency and Symptom Management After Hematopoietic Stem Cell Transplantation: A Theory-Based Randomized Controlled Study
}

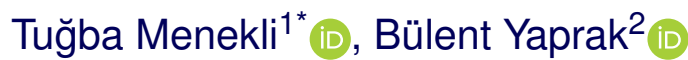

\begin{abstract}
The objective of the research was to determine the effect of educational intervention based on Bandura's Social Cognitive Learning Theory on care dependency and symptom management after hematopoietic stem cell transplantation.

Methods. This randomized controlled trial was conducted between January 2019 and February 2020 at the Hematopoietic Stem Cell Transplantation Center. All the patients were randomly divided into two groups: 53 individuals in the intervention group and 53 individuals in the control group. The sociodemographic data collection form, the Edmonton Symptom Assessment Scale and the Care Dependency Scale were used for data collection. Data were collected from the patients one day after hematopoietic stem cell transplantation and 12 weeks later.

Results. There were no statistically significant differences between the groups regarding the mean scores of the Edmonton Symptom Assessment Scale and the Care Dependency Scale at baseline. Twelve weeks after intervention, there were statistically significant differences between the groups regarding the mean scores of the Edmonton Symptom Assessment Scale and the Care Dependency Scale.

Conclusions. Educational intervention along with telephone counseling based on Bandura's theory was found to be an effective way to reduce symptom severity and care dependency in patients who underwent hematopoietic stem cell transplantation and is recommended for all patients after hematopoietic stem cell transplantation.
\end{abstract}

\section{Keywords}

Educational Intervention; Care Dependency; Symptom Management; Bandura's Social Cognitive Theory; Hematopoietic Stem Cell Transpantation

${ }^{1}$ Department of Internal Medicine Nursing, Malatya Turgut Özal University, Faculty of Health Sciences, Battalgazi, Malatya, Turkey ${ }^{2}$ Department of Internal Medicine, Malatya Turgut Özal University, Faculty of Medicine, Battalgazi, Malatya, Turkey

${ }^{*}$ Corresponding author: tugbamenekli2013@gmail.com

Copyright @Tuğba Menekli, Bülent Yaprak, 2021

\section{Introduction}

Cancer is a global health issue. Even though the death rates of cancer have significantly decreased in recent decades, its prevalence remains high. According to the World Health Organization's (WHO) GLOBOCAN 2020 report, 19.2 million new cases and 9.9 million cancer deaths occurred in 2020. About 1.3 million of these cases were diagnosed with non-Hodgkin lymphoma, leukemia, multiple myeloma, Hodgkin lymphoma [1].

Hematopoietic stem cell transplantation (HSCT) is a common treatment for hematologic malignancies such as non-Hodgkin lymphoma, leukemia, multiple myeloma, Hodgkin lymphoma. In the United States, by 2014, about
340, 000 cumulative HSCTs were reported to be performed and in 2018, 22, 729 HSCTs were performed [2, 3]. HSCT trends have increased in non-malignant and malignant diseases as well [4]. However, after transplantation, patients who were hospitalized for 3 or 4 weeks experienced some complications and symptoms that mostly started before transplantation and remained high even 100 days after transplantation; moreover, symptoms lasted for about two years $[5,6]$.

The reasons for these complications and symptoms were HCTS itself and side effects of therapies used in addition to HSCT, including chemotherapy, radiotherapy, immunosuppression [7-10]. After HSCT, patients experienced physical, physiological, and social problems. Fre- 
quently occurring physical symptoms included loss of appetite, skin, eye, and mouth problems, sleep difficulties, fatigue, while physiological problems included distress, anxiety, and depression [7]. Especially patients' physical well-being was adversely affected after the reinfusion phases [11].

In the literature, these symptoms and complications have been reported to negatively affect the patients' quality of life (QoL) $[6,12,13]$. One of the main objectives of nursing care is to improve the patients' QoL. Therefore, nurses need to control these symptoms. Nurses are primarily responsible for general care of patients in the hospital and their education to maintain symptom management when patients are discharged from the hospital [8]. In addition, patient follow-up has been reported to be important to improve the patient's QoL and reduce symptom severity $[8,14,15]$.

Patients' care dependency is associated with their symptom burden. As the patient's symptom and its severity increase, patient's dependency on care increases as well [16, 17]. For this reason, symptom management is important to decrease patients' care dependency as well. Treatmentrelated symptoms of HSCT last for about two years [5, 6]. Thus, self-management is a crucial part of symptom management in these patients. The WHO strongly recommends the implementation of self-management interventions in long-term care [18]. Guiding patients about their selfmanagement is important to increase their self-efficacy.

Bandura's Social Cognitive Learning Theory is a theory of the learning process. The theory states that learning is a cognitive process occurring in a social context because we learn from our interactions with others. There are four steps of learning: attention, retention, reproduction, and motivation. Perceived self-efficacy is an important component of reproduction and motivation $[19,20]$. Thus, improving self-efficacy is a key factor to maintain the management of symptoms such as long-term diseases [18]. As evaluating the persons' ability to manage symptoms is a cognitive process, the patients' perception of their ability is a key factor to determine the problems and to improve symptom management. According to Bandura, the development of self-efficacy is the way to create a target behavior in patients [18]. Educational interventions have been reported as an effective way to improve patients' self-efficacy in specific groups of diseases such as asthma, diabetic foot, chronic kidney disease, and some types of cancer [21-25]. However, there is a gap in studies evaluating the effect of educational intervention on self-management in postHSCT patients.

The objective of the research was to determine the effect of educational intervention on care dependency and symptom management in post-HSCT patients.

\section{Materials and Methods}

\section{Study Design}

The study was of a randomized controlled design (Fig. 1).

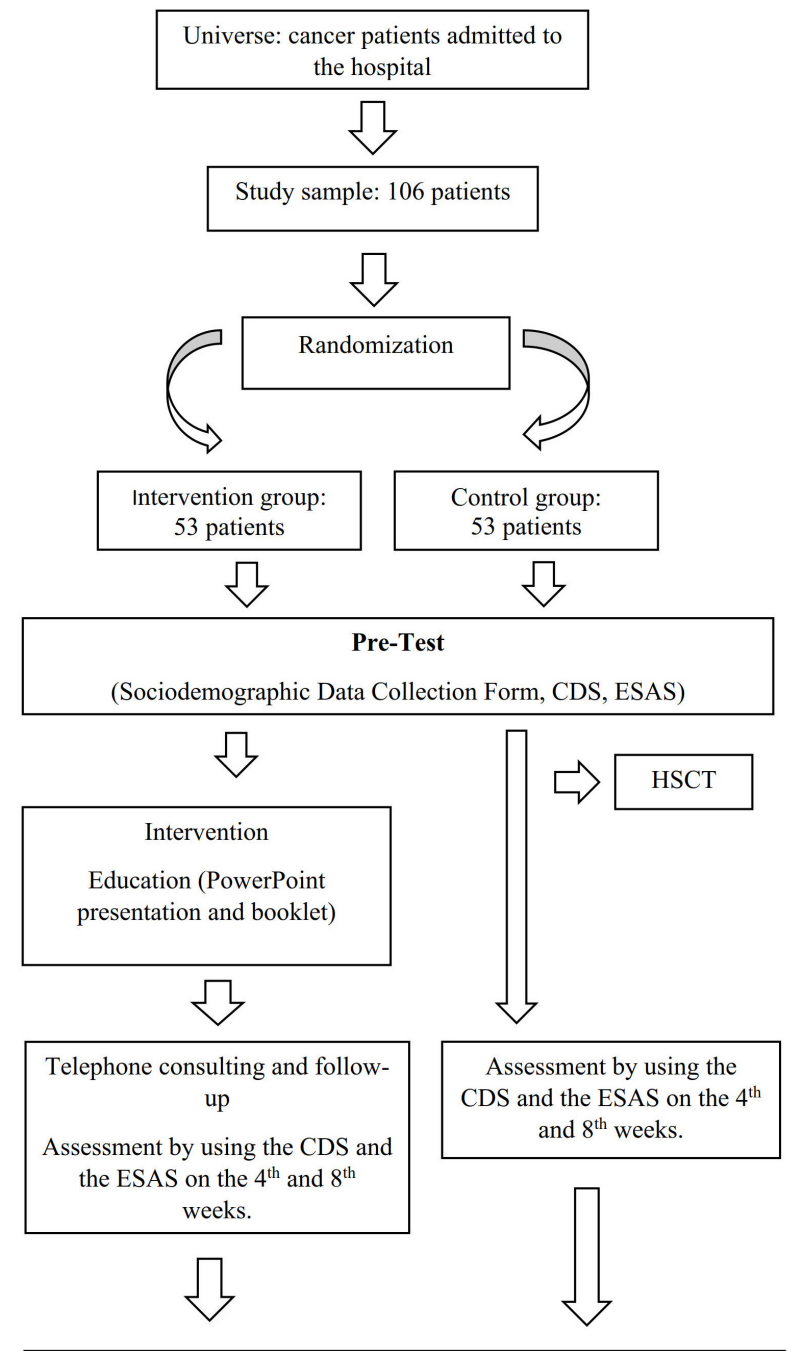

Post-test assessment by using the CDS and the ESAS on the $12^{\text {th }}$ week

Figure 1. Flow diagram of the study.

\section{Study Setting and Sample}

The study was carried out at the Hematopoietic Stem Cell Transplantation Center of University Hospital between January 2019 and February 2020. Power analysis was used for sample determination: the minimum required sample was determined as 45 for each group and 90 in total $(\alpha=0.05$, $0.95 \mathrm{CI}, \mathrm{d}=0.70$, actual power $=0.95$ ). Considering the potential data lost during the follow-up period, the study was carried out with 106 (53 individuals per group) patients who were divided into two groups, the intervention and control groups, by using computer-assisted simple randomization.

\section{Inclusion Criteria}

- patients diagnosed with cancer (for 6 months or more);

- patients selected for treatment with HSCT;

- patients at the age of 18 years and older;

- patients able to communicate in Turkish;

- patients able to use a mobile phone (to answer a phone call and read messages); 
- patients agreed to participate in the study.

\section{Data Collection}

Data collection started before patients received HSCT at the center. The sociodemographic data collection form was introduced to patients before their treatment. One day after treatment (pre-test), the Edmonton Symptom Assessment Scale (ESAS) and the Care Dependency Scale (CDS) were proposed to patients. The ESAS and CDS assessments were repeated on the $4^{\text {th }}, 8^{\text {th }}$, and $12^{\text {th }}$ weeks after treatment (Fig. 1). Face-to-face interviews were used during the pretest and the $12^{\text {th }}$ week, while phone calls were used for data collection on the $4^{\text {th }}$ and $8^{\text {th }}$ weeks. However, there was data missing for the $4^{\text {th }}$ and $8^{\text {th }}$ weeks as some patients did not answer phone calls, and other patients rejected to answer any questions. For this reason, the data of these weeks were not analyzed.

\section{Sociodemographic Data Collection Form}

This form was developed by researchers after literature review [8, 10, 26, 27] and consisted of 10 items, including age, gender, marital status, number of children, education level, working status, income level, diagnosis, disease duration, and type of transplantation (autologous and allogeneic). All information was self-reported and collected from patients.

\section{Care Dependency Scale}

The scale was developed by Dijkstra [28] and includes various physical and psychological aspects, providing a comprehensive assessment of patient's care dependence [28]. The validity and reliability of the Turkish version were assessed by Hakverdioğlu et al. [29]. The original version of the scale consists of 15 items assessing eating and drinking, incontinence, body posture, mobility, day and night patterns, getting dressed and undressed, body temperature, hygiene, avoidance of danger, communication, contact with others, sense of rules and values, daily activities, recreational activities, and learning ability. During its Turkish adaptation, two new items, namely memory and pray, were added to the scale and, therefore, the Turkish version consists of 17 items. The responses for the items range from 1 (completely dependent) to 5 (completely independent) points. Accordingly, the scores of the scale range from 17 and 85 . Higher points reflect lower patient's dependency. In the current study, Cronbach's alpha value was 0.90 .

\section{Edmonton Symptom Assessment Scale}

The scale was created by a group of palliative care physicians working at the University of Alberta, Edmonton, Alberta, Canada. The scale was developed to assess the intensity of nine common symptoms experienced by cancer patients, including pain, tiredness, nausea, depression, anxiety, drowsiness, appetite, well-being, and shortness of breath. Patients score the severity of each symptom from 0 to 10 , where 0 means the absence of the symptom, and 10 means the worst possible severity of the symptom. The Turkish validity and reliability of the scale were assessed by Sadırlı and Ünsar in 2008. In the Turkish version, other common symptoms, including skin and nail changes, oral sores, hand numbness, were added. Thus, the Turkish version of the scale consists of 11 items [30]. Cronbach's alpha of the Turkish version of the scale was reported as 0.83 [30]. Cronbach's alpha in this study was found to be 0.82 .

\section{Interventions}

A printed booklet for educating patients was prepared after reviewing the literature $[26,27,31,32]$. The booklet was evaluated by 10 different professionals, namely two hematologists, four hematology nurses, and four nursing academicians. The booklet was revised with regards to experts' opinions before its use in patient education.

Prior to HSCT, the researcher introduced herself and the study to the patient. A verbal and written permission was obtained from patients before the study. The sociodemographic data collection form was offered to patients. The ESAS and the CDS questionaries were used one day after HSCT. This first assessment was considered as the baseline for the study.

In the intervention group, patients were educated by means of a booklet and PowerPoint presentation after the initial assessment. All educations were carried out by the same researcher and took approximately one hour per patient. The training content was as follows: (1) the introduction and discussion of expectations; (2) the identification and types of possible post-transplant complications; (3) common post-transplant symptoms and their management (constipation, diarrhea, hair loss, anorexia, anemia, infection, bleeding, nausea/vomiting, pain, fatigue, mouth and gum problems, sleep difficulties, sexual problems, psychological problems); (4) the measures to alleviate possible posttransplant symptoms; (5) the information about who they can contact when they need support and when they need to apply to the hospital. A PowerPoint presentation was used, and a booklet was provided to each patient. After presentation, the researcher asked patients if they had any questions and all patients' questions were answered by the researcher. After patients were discharged from the hospital, education was followed by telephone counseling. Twice a week, text messages were sent to patients to inform and remind them about symptom management. Patients' questions were answered by the researcher. The frequency of patients' calls for a question ranged between 8 and 17 per week. Patients were assessed on the $4^{\text {th }}, 8^{\text {th }}$, and $12^{\text {th }}$ weeks by using the ESAS and CDS via telephone interviews. There are four sources of information to assess the individuals' selfefficacy: performance outcomes, vicarious experiences, verbal persuasion, and physiological feedback [33, 34]. Performance outcomes were assessed by using the ESAS questionnaire; for verbal persuasion, telephone counseling was used, and patients were encouraged by the researcher; to provide vicarious experiences to patients, other patients' positive outcomes in symptom management due to this education were shared with patients of the intervention group. However, face-to-face meeting and experience sharing were not carried out due to the high risk of infection in these groups.

For patients in the control group, routine hospital care 
was provided. These patients were informed by nurses in their wards without any presentation or a booklet. They were offered the ESAS and CDS assessments only after their discharge from the hospital. There wasn't any telephone counseling.

\section{Data Analysis}

Data of the study were analyzed by using IBM SPSS v25 software. G-power 3.1.9.4 software was used for sample calculation. Descriptive findings of the study were presented as the number (n), the percentage (\%), the mean, standard deviation, the median, and the minimal and maximal values. The Shapiro-Wilk test was used to evaluate the normal distribution of data. After determining the normal distribution of data, the Paired sample t-test was used to determine changes in the ESAS and CDS mean score over time. The Independent sample t-test was used for comparing the mean scores of the ESAS and CDS between the intervention and control groups. The Chi-Square test was used to determine the differences in sociodemographic characteristics between the intervention and control groups.

\section{Results}

Sociodemographic and disease-related characteristics of patients in the intervention and control groups are demonstrated in Table 1. Both groups did not differ significantly in all characteristics.

There was no statistically significant difference between the groups in the ESAS mean scores at baseline $(p>0.05)$; there was a statistically significant difference between the groups in the post-test regarding the mean scores of the ESAS and symptoms $(\mathrm{p}<0.05)$ (Table 2$)$.

There was no statistically significant difference between the groups in the CDS mean scores at basebaseline $(p>0.05)$; there was a statistically significant difference between the groups in the post-test regarding the CDS mean scores and its subdomains $(\mathrm{p}<0.05)$ (Table 3$)$.

The interventional group was characterized by significantly lower mean score value of the ESAS and higher mean score value of the CDS 12 weeks after intervention (Table 4). Educational intervention had a large effect on the severity of symptoms (Cohen's $d=1.364$ ) and patients' care dependency (Cohen's d = 0.815).

\section{Discussion}

HSCT is a common treatment worldwide [2]. However, it causes many symptoms experienced by patients following the treatment and discharge [5, 8]. These symptoms persist for up two years and require behavior change $[5,6]$. Bandura, in his Social Cognitive Learning Theory, has suggested that increasing individual's self-efficacy is a key point to achieve outcomes [33]. In the current study, educational intervention, one of the best ways to increase self-efficacy, was used to increase patients' self-efficacy in symptom management [33]. Patients' performance outcomes were measured via evaluating the severity of their symptoms with the ESAS. We measured patients' care dependency as well since we expected a decrease in their care dependency with an increase in their symptom management.

In the current study, we found that tiredness had the highest score on the ESAS scale followed by well-being, appetite, and depression. Fatigue was one of the most common symptoms among cancer patients, especially after treatment. Accordingly, fatigue has been reported as a common symptom in cancer patients after HSCT [35-37]. In a study conducted by Mosher et al. (2011), among QoL concerns, the two most common complains were "I get tired easily" with $56.4 \%$ and "I have lack of energy" with $42.1 \%$ [38]. Our findings on tiredness were consistent with the literature in this respect. Cohen et al. (2012) have reported that patients' physical, social, and functional well-being decreased after HSCT [6]. Similarly, Janicsâk et al. (2013) have reported that patients' physical, social, emotional, and functional well-being decreased after HSCT [39]. In a study comparing the symptoms of cancer patients who underwent HSCT and those who did not undergo HSCT, Ward et al. (2020) have reported that the "lack of appetite" score in patients who underwent HSCT was $10.66 \pm 23.2$, while other cancer patients' score was $6.07 \pm 15.6$ [40]. After HSCT, protective isolation was needed and this contributed to the physiological problems among patients [41]. Mosher et al. (2011) have reported that patients undergoing HSCT were likely to develop depression and females were at higher risk than males [38]. The common symptom profile of our study was in line with the literature.

The mean ESAS scores after transplantation were $46.22 \pm 23.82$ in the intervention group and $42.98 \pm 22.11$ in the control group. Ovayolu et al. (2013) have reported that there was an increase in all ESAS symptoms, except for anxiety, after transplantation [13]. According to Kako et al. (2018), the optimal cut-off values for pain, tiredness, drowsiness, nausea, lack of appetite, and dyspnea were $4,4,4,2,5$, and 4, respectively [42]. In our study, all the scores of these symptoms in the intervention group, except for lack of appetite, were over the cut-off score. In the current study, higher symptom severity scores after transplantation (pre-test) were similar to those from the literature. In the pre-test assessment, the mean CDS scores were $55.87 \pm 24.92$ in the intervention group and $56.90 \pm 29.38$ in the control group. Several studies have showed that an increase in symptoms and their severity led to an increase in care dependency [43, 44]. Accordingly, patients' care dependency was high in both groups.

In this study, we found that educational intervention and telephone counseling based on Bandura's theory were effective to decrease the severity of symptoms and care dependency. Akgün Şahin and Ergüney (2016) have reported that educational intervention was found to be effective in reducing symptom frequency and severity, discomfort level in cancer patients [45]. According to Qiao et al. (2021), patient education was effective in cognitive symptom management [25]. Cioce et al. (2020) have found that educational intervention was effective in terms of QoL and some symptoms experienced by patients who underwent HSCT such as anxiety and depression [31]. A study con- 
Table 1. Comparison of the ESAS and CDS mean scores between groups and pre-test and post-test.

\begin{tabular}{|c|c|c|c|}
\hline & $\begin{array}{c}\text { Intervention group } \\
\mathrm{n}(\%)\end{array}$ & $\begin{array}{c}\text { Control group } \\
\mathrm{n}(\%)\end{array}$ & $\chi^{2} / \mathbf{p}$ \\
\hline \multicolumn{4}{|l|}{ Age groups, years } \\
\hline $18-28$ & $10(18.9)$ & $11(20.7)$ & \multirow{5}{*}{$1.341 / 0.512$} \\
\hline $29-39$ & $16(30.2)$ & $17(32.1)$ & \\
\hline $40-50$ & $14(26.4)$ & $14(26.4)$ & \\
\hline $51-61$ & $9(17.0)$ & $8(15.1)$ & \\
\hline 62 and older & $4(7.5)$ & $3(5.7)$ & \\
\hline \multicolumn{4}{|l|}{ Gender } \\
\hline Female & $25(47.2)$ & $25(47.2)$ & \multirow[t]{2}{*}{$0.641 / 0.423$} \\
\hline Male & $28(52.8)$ & $28(52.8)$ & \\
\hline \multicolumn{4}{|l|}{ Marital status } \\
\hline Married & $36(67.9)$ & $34(64.2)$ & \multirow[t]{2}{*}{$0.216 / 0.398$} \\
\hline Single & $17(32.1)$ & $19(35.8)$ & \\
\hline \multicolumn{4}{|l|}{ Having a child } \\
\hline Yes & $33(62.3)$ & $32(60.4)$ & \multirow[t]{2}{*}{$1.135 / 0.287$} \\
\hline No & $20(37.7)$ & $21(39.6)$ & \\
\hline \multicolumn{4}{|l|}{ Education level } \\
\hline Primary school & $25(47.2)$ & $24(45.3)$ & \multirow{3}{*}{$1.096 / 0.578$} \\
\hline High school & $20(37.7)$ & $22(41.5)$ & \\
\hline University degree & $8(15.1)$ & $7(13.2)$ & \\
\hline \multicolumn{4}{|l|}{ Profession } \\
\hline Employee & $32(60.4)$ & $34(64.2)$ & \multirow{3}{*}{$1.390 / 0.499$} \\
\hline Housewife & $15(28.3)$ & $12(22.6)$ & \\
\hline Retired & $6(11.3)$ & $7(13.2)$ & \\
\hline \multicolumn{4}{|l|}{ Income Level } \\
\hline Income is higher than the expenses & $16(30.2)$ & $14(26.4)$ & \multirow{3}{*}{$0.526 / 0.432$} \\
\hline Income is equal to the expenses & $29(54.7)$ & $30(56.6)$ & \\
\hline Income is lower than the expenses & $8(15.1)$ & $9(17.0)$ & \\
\hline \multicolumn{4}{|l|}{ Disease } \\
\hline Multiple myeloma & $13(24.5)$ & $12(22.6)$ & \multirow{3}{*}{$1.395 / 0.228$} \\
\hline Lymphoma & $14(26.4)$ & $16(30.2)$ & \\
\hline Leukemia & $26(49.1)$ & $25(47.2)$ & \\
\hline \multicolumn{4}{|l|}{ Disease duration } \\
\hline $0-1$ year & $17(32.1)$ & $14(26.4)$ & \multirow{3}{*}{$1.604 / 0.691$} \\
\hline $1-2$ years & $25(47.2)$ & $27(50.9)$ & \\
\hline 2 years or more & $11(20.7)$ & $12(22.7)$ & \\
\hline \multicolumn{4}{|l|}{ Transplantation type } \\
\hline Autologous & $26(49.1)$ & $24(45.3)$ & \multirow[t]{2}{*}{$1.135 / 0.287$} \\
\hline Allogenic & $27(50.9)$ & $29(54.7)$ & \\
\hline
\end{tabular}

Table 2. Mean scores of the ESAS in groups before and after education.

\begin{tabular}{lcccccc}
\hline & \multicolumn{2}{c}{ Pre-test } & \multicolumn{3}{c}{ Post-test } \\
\cline { 2 - 7 } & Intervention group & Control group & $\mathrm{p}$ & Intervention group & Control group & $\mathrm{p}$ \\
\hline Pain & $4.03 \pm 2.11$ & $4.67 \pm 2.48$ & 0.103 & $2.80 \pm 1.10$ & $5.12 \pm 2.15$ & 0 \\
Tiredness & $5.95 \pm 2.73$ & $5.14 \pm 2.06$ & 0.215 & $3.04 \pm 1.79$ & $6.00 \pm 2.44$ & 0 \\
Nausea & $2.40 \pm 2.26$ & $2.55 \pm 2.10$ & 0.167 & $1.16 \pm 0.80$ & $3.95 \pm 1.26$ & 0 \\
Depression & $5.13 \pm 2.18$ & $5.30 \pm 2.33$ & 0.181 & $2.71 \pm 1.05$ & $5.32 \pm 2.30$ & 0 \\
Anxiety & $4.80 \pm 2.53$ & $4.26 \pm 2.07$ & 0.205 & $3.53 \pm 1.94$ & $5.10 \pm 2.43$ & 0 \\
Drowsiness & $5.12 \pm 2.14$ & $5.05 \pm 2.15$ & 0.328 & $3.66 \pm 2.14$ & $5.48 \pm 2.16$ & 0.002 \\
Lack of appetite & $5.53 \pm 2.99$ & $4.19 \pm 2.72$ & 0.96 & $3.12 \pm 1.70$ & $5.22 \pm 2.01$ & 0 \\
Well-being & $5.80 \pm 2.34$ & $5.25 \pm 2.01$ & 0.236 & $3.14 \pm 1.86$ & $6.37 \pm 2.99$ & 0 \\
Shortness of breath & $2.43 \pm 2.72$ & $2.11 \pm 2.26$ & 0.772 & $1.30 \pm 0.75$ & $3.54 \pm 1.30$ & 0.003 \\
Skin and nail changes & $1.90 \pm 0.35$ & $1.58 \pm 0.21$ & 0.788 & $0.83 \pm 0.31$ & $2.16 \pm 1.02$ & 0.001 \\
Oral sores & $1.53 \pm 0.74$ & $1.05 \pm 0.73$ & 0.103 & $0.50 \pm 0.46$ & $1.98 \pm 0.94$ & 0.003 \\
Hand numbness & $1.60 \pm 0.73$ & $1.83 \pm 0.99$ & 0.096 & $1.01 \pm 0.91$ & $2.30 \pm 1.22$ & 0.008 \\
\hline
\end{tabular}


Table 3. Mean scores of the CDS in groups before and after education.

\begin{tabular}{lcccccc}
\hline & \multicolumn{3}{c}{ Pre-test } & \multicolumn{3}{c}{ Post-test } \\
\cline { 2 - 7 } & Intervention group & Control group & $\mathrm{p}$ & Intervention group & Control group & $\mathrm{p}$ \\
\hline Eating/drinking & $3.22 \pm 1.52$ & $3.54 \pm 1.09$ & 0.15 & $4.34 \pm 1.90$ & $2.00 \pm 1.39$ & 0 \\
Incontinence & $3.11 \pm 1.10$ & $3.18 \pm 1.41$ & 0.135 & $4.88 \pm 1.73$ & $3.14 \pm 1.44$ & 0 \\
Body posture & $3.73 \pm 1.59$ & $3.20 \pm 1.85$ & 0.183 & $4.63 \pm 1.80$ & $3.24 \pm 1.13$ & 0 \\
Mobility & $3.65 \pm 1.48$ & $3.54 \pm 1.19$ & 0.171 & $4.32 \pm 1.66$ & $2.82 \pm 1.28$ & 0 \\
Day/night pattern & $3.19 \pm 1.04$ & $3.60 \pm 1.68$ & 0.284 & $4.69 \pm 1.54$ & $3.20 \pm 1.43$ & 0 \\
Getting (un)dressed & $3.07 \pm 1.75$ & $3.48 \pm 1.27$ & 0.366 & $4.52 \pm 1.85$ & $2.50 \pm 1.37$ & 0.001 \\
Body temperature & $3.65 \pm 1.51$ & $3.42 \pm 1.55$ & 0.537 & $4.90 \pm 1.49$ & $3.46 \pm 1.93$ & 0 \\
Hygiene & $2.00 \pm 1.56$ & $2.34 \pm 1.11$ & 0.258 & $3.97 \pm 1.01$ & $3.56 \pm 1.98$ & 0 \\
Avoidance of danger & $2.44 \pm 1.43$ & $2.52 \pm 1.07$ & 0.439 & $3.42 \pm 1.42$ & $2.44 \pm 3.09$ & 0 \\
Communication & $4.00 \pm 1.81$ & $3.95 \pm 1.03$ & 0.708 & $4.94 \pm 1.31$ & $3.08 \pm 1.02$ & 0.001 \\
Contact with others & $3.90 \pm 1.48$ & $4.02 \pm 1.99$ & 0.291 & $4.51 \pm 1.39$ & $3.90 \pm 1.96$ & 0.003 \\
Pray & $3.44 \pm 1.93$ & $3.50 \pm 1.70$ & 0.11 & $4.97 \pm 1.58$ & $3.30 \pm 1.25$ & 0.005 \\
Sense of rules/values & $3.37 \pm 1.06$ & $3.50 \pm 1.45$ & 0.099 & $4.23 \pm 1.77$ & $3.30 \pm 1.20$ & 0.004 \\
Daily activities & $2.44 \pm 1.93$ & $2.50 \pm 1.04$ & 0.134 & $3.15 \pm 1.61$ & $2.30 \pm 3.06$ & 0.003 \\
Recreational activities & $3.44 \pm 1.80$ & $3.50 \pm 1.29$ & 0.336 & $4.20 \pm 1.01$ & $3.30 \pm 3.97$ & 0.003 \\
Memory & $3.82 \pm 1.05$ & $3.69 \pm 1.13$ & 0.552 & $4.37 \pm 1.00$ & $3.60 \pm 2.85$ & 0.004 \\
Learning ability & $3.40 \pm 1.77$ & $3.46 \pm 1.80$ & 0.237 & $3.95 \pm 1.48$ & $3.41 \pm 2.62$ & 0.003 \\
\hline
\end{tabular}

Table 4. Comparison of the ESAS and CDS mean scores between groups and pre-test and post-test.

\begin{tabular}{clcccc}
\hline & & $\begin{array}{c}\text { Intervention } \\
\text { group }\end{array}$ & Control group & $\mathrm{t}$ & $\mathrm{p}$ \\
\hline \multirow{4}{*}{ ESAS } & Pre-test & $46.22 \pm 23.82$ & $42.98 \pm 22.11$ & -0.218 & $0.623^{* *}$ \\
& Post-test & $26.80 \pm 14.81$ & $52.54 \pm 22.22$ & 6.139 & $<0.001^{* *}$ \\
& $\mathrm{t}$ & -2.662 & 3.171 & & \\
& $\mathrm{p}$ & $0.010^{*}$ & $0.002^{*}$ & & $0.579^{* *}$ \\
& Pre-test & $55.87 \pm 24.92$ & $56.90 \pm 29.38$ & 0.134 & $<0.001^{* *}$ \\
& Post-test & $73.98 \pm 25.11$ & $52.55 \pm 27.40$ & -5.703 & \\
& $\mathrm{t}$ & 6.94 & 10.659 & & \\
& $\mathrm{p}$ & $0.001^{*}$ & $0.003^{*}$ & & \\
\hline
\end{tabular}

Notes: * Paired-sample t-test; **Independent sample t-test.

ducted by Sherman et al. (2012) has revealed that psychoeducation plus telephone counseling was effective to improve patients' overall health, psychological well-being, and social adjustment [46]. On the other hand, according to several studies, educational intervention was an effective way to improve self-efficacy in various conditions as well [22, 24, 25]. Hoffman (2013) has reported that enhancing self-efficacy was essential for optimizing cancer outcomes in patients [18]. An increase in self-efficacy is known to lead to an increase in patients' self-management. As patients' self-management increase, their care dependency and symptom decrease. For nurses, it is difficult to manage symptoms after HSCT and to decrease the patients' level of care dependency; however, theories, especially best-studied theories such as Bandura's Social Cognitive Learning Theories, help nurses manage such challenging conditions, as they explain the learning process of the individuals and which inputs and interventions are needed to improve knowledge and to develop behavior [8, 18, 22, 24]. Performance outcomes (symptom severity and care dependency) in our study supported Bandura's Social Cognitive Learning Theory.

We found that educational intervention had a great effect on symptom severity and care dependency in patients after HSCT. However, the framework for the study was that of a complex intervention as described by the UK Medical Research Council [47]. Within this framework, it is difficult to isolate the effect of intervention. A single study reveals only one aspect of intervention and multiple studies are required to elucidate any effect more clearly. Thus, more studies are needed to support this effect on symptom severity and care dependency.

\section{Limitations}

The study was carried out in a single-center design; the sample of the study was limited and consisted of 106 patients. Further studies involving larger groups and different populations are needed.

\section{Conclusions}

Patients' care dependency and symptom severity after HSCT were high. Educational intervention based on Bandura's theory was found to be an effective way to decrease patients' care dependency and symptom severity. 


\section{Recommendations}

Nurses are recommended to use Bandura's theory in educating patients after HSCT, combining this education and telephone counseling. Nursing curricula need to include these types of theories, e.g., Bandura's Social Cognitive Learning Theory, to manage such complex patients' conditions. These theories should be incorporated into clinical training for nurses as well.

\section{Ethical Statement}

Prior to the research, ethical approval from the the İnönü Üniversity Non-Interventional Clinical Research Ethics Comittee (Date:15.11.2018; Decision Number: 2018-11/20) and written permission from the institution where the research was conducted were obtained. The study was conducted by following the Principles of the Declaration of Helsinki.

\section{Informed Consent}

The informed consent forms were applied after the participants were informed about the study and their informed consent was obtained.

\section{Acknowledgments}

We thank all patients for their collaboration.

\section{Conflict of Interest}

The authors declare that no conflicts exist.

\section{Financial Disclosure}

The authors declared no financial support.

\section{References}

[1] Sung H, Ferlay J, Siegel RL, Laversanne M, Soerjomataram I, Jemal A, et al. Global cancer statistics 2020: GLOBOCAN estimates of incidence and mortality worldwide for 36 cancers in 185 countries. CA: A Cancer Journal for Clinicians. 2021;71(3):209-249. Available from: https://doi.org/10.3322/caac.21660

[2] Broder MS, Quock TP, Chang E, Reddy SR, Agarwal-Hashmi R, Arai $S$, et al. The cost of hematopoietic stem-cell transplantation in the United States. American health \& drug benefits. 2017;10(7):366-374. Available from: https://pubmed.ncbi.nlm.nih.gov/29263771/

[3] Health Resources \& Services Administration. Transplant Activity Report [Internet]. 2021 [cited 2021 Aug 16]. Available from: https://bloodstemcell.hrsa.gov/data/donation-andtransplantation-statistics/transplant-activity-report

[4] Khandelwal P, Millard HR, Thiel E, Abdel-Azim H, Abraham AA, Auletta JJ, et al. Hematopoietic stem cell transplantation activity in pediatric cancer between 2008 and 2014 in the United States: a Center for International Blood and Marrow Transplant research report. Biology of Blood and Marrow Transplantation. 2017;23(8):1342-1349. Available from: https://doi.org/10.1016/j.bbmt.2017.04.018

[5] El-Jawahri A, LeBlanc T, VanDusen H, Traeger L, Greer JA, Pirl WF, et al. Effect of inpatient palliative care on quality of life 2 weeks after hematopoietic stem cell transplantation. JAMA. 2016;316(20):2094. Available from: https://doi.org/10.1001/jama.2016.16786

[6] Cohen MZ, Rozmus CL, Mendoza TR, Padhye NS, Neumann J, Gning I, et al. Symptoms and quality of life in diverse patients undergoing hematopoietic stem cell transplantation. Journal of Pain and Symptom Management. 2012;44(2):168-180. Available from: https://doi.org/10.1016/j.jpainsymman.2011.08.011

[7] Kroemeke A, Sobczyk-Kruszelnicka M, KwissaGajewska Z. Everyday life following hematopoietic stem cell transplantation: decline in physical symptoms within the first month and change-related predictors. Quality of Life Research. 2017;27(1):125-135. Available from: https://doi.org/10.1007/s11136-0171705-3

[8] Akin S, Oguz G, Durna Z. Symptoms after hospital discharge following hematopoietic stem cell transplantation. Indian Journal of Palliative Care. 2014;20(1):41. Available from: https://doi.org/10.4103/09731075.125558

[9] Majhail NS, Douglas Rizzo J, Lee SJ, Aljurf M, Atsuta Y, Bonfim C, et al. Recommended screening and preventive practices for long-term survivors after hematopoietic cell transplantation. Hematology/Oncology and Stem Cell Therapy. 2012;5(1):1-30. Available from: https://doi.org/10.5144/16583876.2012.1

[10] Bevans M, Wehrlen L, Castro K, Prince P, Shelburne N, Soeken $\mathrm{K}$, et al. A problem-solving education intervention in caregivers and patients during allogeneic hematopoietic stem cell transplantation. Journal of Health Psychology. 2013;19(5):602-617. Available from: https://doi.org/10.1177/1359105313475902

[11] Garcia CM, Mumby PB, Thilges S, Stiff PJ. Comparison of early quality of life outcomes in autologous and allogeneic transplant patients. Bone Marrow Transplantation. 2012;47(12):1577-1582. Available from: https://doi.org/10.1038/bmt.2012.77

[12] Nelson AM, Coe CL, Juckett MB, Rumble ME, Rathouz PJ, Hematti P, et al. Sleep quality following hematopoietic stem cell transplantation: longitudinal trajectories and biobehavioral correlates. Bone Marrow Transplantation. 2014;49(11):1405-1411. Available from: https://doi.org/10.1038/bmt.2014.179 
[13] Ovayolu Ö, Ovayolu N, Kaplan E, Pehlivan M, Karadağ G. Symptoms and quality of life before and after stem cell transplantation in cancer. Pakistan Journal of Medical Sciences. 2013;29(3). Available from: https://doi.org/10.12669/pjms.293.3290

[14] Bhatia S. Long-term health impacts of hematopoietic stem cell transplantation inform recommendations for follow-up. Expert Review of Hematology. 2011;4(4):437-454. Available from: https://doi.org/10.1586/ehm.11.39

[15] Passweg J, Halter J, Bucher C, Gerull S, Heim D, Rovó A, et al. Hematopoietic stem cell transplantation: a review and recommendations for follow-up care for the general practitioner. Swiss Medical Weekly. 2012;Available from: https://doi.org/10.4414/smw.2012.13696

[16] Lazenby M, Sebego M, Swart NC, Lopez L, Peterson K. Symptom burden and functional dependencies among cancer patients in Botswana suggest a need for palliative care nursing. Cancer Nursing. 2016;39(1):E29-E38. Available from: https://doi.org/10.1097/NCC.0000000000000249

[17] Oechsle K, Wais MC, Vehling S, Bokemeyer C, Mehnert A. Relationship between symptom burden, distress, and sense of dignity in terminally ill cancer patients. Journal of Pain and Symptom Management. 2014;48(3):313-321. Available from: https://doi.org/10.1016/j.jpainsymman.2013.10.022

[18] Hoffman AJ. Enhancing self-efficacy for optimized patient outcomes through the theory of symptom self-management. Cancer Nursing. 2013;36(1):E16-E26. Available from: https://doi.org/10.1097/NCC.0b013e31824a730a

[19] Decker PJ. The enhancement of behavior modeling training of supervisory skills by the inclusion of retention processes. Personnel Psychology. 1982;35(2):323-332. Available from: https://doi.org/10.1111/j.1744-6570.1982.tb02198.x

[20] Bethards ML. Applying social learning theory to the observer role in simulation. Clinical Simulation in Nursing. 2014;10(2):e65-e69. Available from: https://doi.org/10.1016/j.ecns.2013.08.002

[21] Kocaaslan EN, Akgün Kostak M. Effect of disease management education on the quality of life and selfefficacy levels of children with asthma. Journal for Specialists in Pediatric Nursing. 2019;24(2):e12241. Available from: https://doi.org/10.1111/jspn.12241

[22] Toygar İ, Hançerlioğlu S, Utku T, Şimşir IY, Çetinkalp Ş. Effect of an educational intervention based on Bandura's theory on foot care selfefficacy in diabetes: a prospective quasi-experimental study. The International Journal of Lower Extremity Wounds. 2020;:153473462094832. Available from: https://doi.org/10.1177/1534734620948327
[23] Lee M, Wu SV, Lu K, Liu C, Liang S, Chuang Y. Effectiveness of a self-management program in enhancing quality of life, self-care, and self-efficacy in patients with hemodialysis: a quasi-experimental design. Seminars in Dialysis. 2021;34(4):292-299. Available from: https://doi.org/10.1111/sdi.12957

[24] Kav S, Tokdemir G. The effect of structured education to patients receiving oral agents for cancer treatment on medication adherence and self-efficacy. Asia-Pacific Journal of Oncology Nursing. 2017;4(4):290. Available from: https://doi.org/10.4103/apjon.apjon_35_17

[25] Qiao L, Zeng S-Q, Zhang N. Effects of cooperative nursing and patient education on postoperative infection and self-efficacy in gastrointestinal tumors. World Journal of Clinical Cases. 2021;9(7):1610-1618. Available from: https://doi.org/10.12998/wjcc.v9.i7.1610

[26] Gladbach C, Patton LJ, Xu X, Aquino V. Transition from hospital to home following hematopoietic stem cell transplantation: a feasibility study for "Rooming In". Journal of Pediatric Oncology Nursing. 2020;38(1):42-50. Available from: https://doi.org/10.1177/1043454220958643

[27] Leppla L, Mielke J, Kunze M, Mauthner O, Teynor A, Valenta $\mathrm{S}$, et al. Clinicians and patients perspectives on follow-up care and eHealth support after allogeneic hematopoietic stem cell transplantation: a mixed-methods contextual analysis as part of the SMILe study. European Journal of Oncology Nursing. 2020;45:101723. Available from: https://doi.org/10.1016/j.ejon.2020.101723

[28] Dijkstra A, Buist G, Dassen T. Nursing-care dependency. Scandinavian Journal of Caring Sciences. 1996;10(3):137-143. Available from: https://doi.org/10.1111/j.1471-6712.1996.tb00326.x

[29] Yönt G, Akın Korhan E, Khorshid L, Eşer İ, Dijkstra A. Evaluation of the validity and reliability of care dependency scale for elderly individuals. Turkish Journal of Geriatrics. 2010;13(Supp.):71.

[30] Sadırlı S, Ünsar S. Edmonton Symptom Assessment Scale (ESAS) in patients with cancer: the Turkish study of validity and reliability. Firat Saglık Hizmetleri Dergisi. 2009;4(11):79-95.

[31] Cioce M, Lohmeyer FM, Moroni R, Magini M, Giraldi $\mathrm{A}$, Garau $\mathrm{P}$, et al. Impact of educational interventions on psychological distress during allogeneic hematopoietic stem cell transplantation: a randomized study. Mediterranean Journal of Hematology and Infectious Diseases. 2020;12(1):e2020067. Available from: https://doi.org/10.4084/mjhid.2020.067 
[32] Battiwalla M, Hashmi S, Majhail N, Pavletic S, Savani BN, Shelburne N. National Institutes of Health Hematopoietic Cell Transplantation Late Effects Initiative: developing recommendations to improve survivorship and long-term outcomes. Biology of Blood and Marrow Transplantation. 2017;23(1):6-9. Available from: https://doi.org/10.1016/j.bbmt.2016.10.020

[33] Hodges CB. Self-efficacy in the context of online learning environments: a review of the literature and directions for research. Performance Improvement Quarterly. 2008;20(3-4):7-25. Available from: https://doi.org/10.1002/piq.20001

[34] Phan HP. The development of english and mathematics self-efficacy: a latent growth curve analysis. The Journal of Educational Research. 2012;105(3):196-209. Available from: https://doi.org/10.1080/00220671.2011.552132

[35] Oberoi S, Robinson PD, Cataudella D, CulosReed SN, Davis H, Duong N, et al. Physical activity reduces fatigue in patients with cancer and hematopoietic stem cell transplant recipients: a systematic review and meta-analysis of randomized trials. Critical Reviews in Oncology/Hematology. 2018;122:52-59. Available from: https://doi.org/10.1016/j.critrevonc.2017.12.011

[36] Ghazikhanian SE, Dorfman CS, Somers TJ, O'Sullivan ML, Fisher HM, Edmond SN, et al. Cognitive problems following hematopoietic stem cell transplant: relationships with sleep, depression and fatigue. Bone Marrow Transplantation. 2016;52(2):279-284. Available from: https://doi.org/10.1038/bmt.2016.248

[37] Jim HSL, Sutton SK, Jacobsen PB, Martin PJ, Flowers ME, Lee SJ. Risk factors for depression and fatigue among survivors of hematopoietic cell transplantation. Cancer. 2016;122(8):1290-1297. Available from: https://doi.org/10.1002/cncr.29877

[38] Mosher CE, DuHamel KN, Rini C, Corner G, Lam J, Redd WH. Quality of life concerns and depression among hematopoietic stem cell transplant survivors. Supportive Care in Cancer. 2010;19(9):1357-1365. Available from: https://doi.org/10.1007/s00520-0100958-y

[39] Janicsák H, Masszi T, Reményi P, Ungvari GS, Gazdag G. Quality of life and its socio-demographic and psychological determinants after bone marrow transplantation. European Journal of Haematology. 2013;91(2):135-140. Available from: https://doi.org/10.1111/ejh.12126

[40] Ward JA, Balian C, Gilger E, Raybin JL, Li Z, Montgomery KE. Electronic symptom assessment in children and adolescents with advanced cancer undergoing hematopoietic stem cell transplantation. Journal of Pediatric Oncology Nursing. 2020;37(4):255-264. Available from: https://doi.org/10.1177/1043454220917686

[41] Tecchio C, Bonetto C, Bertani M, Cristofalo D, Lasalvia A, Nichele I, et al. Predictors of anxiety and depression in hematopoietic stem cell transplant patients during protective isolation. PsychoOncology. 2012;22(8):1790-1797. Available from: https://doi.org/10.1002/pon.3215

[42] Kako J, Kobayashi M, Kanno Y, Ogawa A, Miura T, Matsumoto Y. The optimal cutoff point for expressing revised Edmonton Symptom Assessment System scores as binary data indicating the presence or absence of symptoms. American Journal of Hospice and Palliative Medicine®. 2018;35(11):1390-1393. Available from: https://doi.org/10.1177/1049909118775660

[43] Steenbeek ED, Ramspek CL, van Diepen M, Dekker FW, Achterberg WP. The association between pain perception and care dependency in older nursing home residents: a prospective cohort study. Journal of the American Medical Directors Association. 2021;22(3):676-681. Available from: https://doi.org/10.1016/j.jamda.2020.07.022

[44] Vaes AW, Machado FVC, Meys R, Delbressine JM, Goertz YMJ, Van Herck M, et al. Care dependency in non-hospitalized patients with COVID-19. Journal of Clinical Medicine. 2020;9(9):2946. Available from: https://doi.org/10.3390/jcm9092946

[45] Şahin ZA, Ergüney S. Effect on symptom management education receiving patients of chemotherapy. Journal of Cancer Education. 2015;31(1):101-107. Available from: https://doi.org/10.1007/s13187-015-0801-8

[46] Sherman DW, Haber J, Hoskins CN, Budin WC, Maislin G, Shukla S, et al. The effects of psychoeducation and telephone counseling on the adjustment of women with early-stage breast cancer. Applied Nursing Research. 2012;25(1):3-16. Available from: https://doi.org/10.1016/j.apnr.2009.10.003

[47] Moore GF, Audrey S, Barker M, Bond L, Bonell C, Hardeman W, et al. Process evaluation of complex interventions: Medical Research Council guidance. BMJ. 2015;350(6):h1258-h1258. Available from: https://doi.org/10.1136/bmj.h1258

Received: 2021-08-16

Revision Requested: 2021-09-15

Revision Received: 2021-09-17

Accepted: 2021-09-20 